13

\title{
Допирование несопряженного полимера органическим соединением с двумя устойчивыми энергетическими состояниями
}

\author{
( Д.Д. Карамов, ${ }^{1}$ А.Н. Лачинов, ${ }^{1,2}$ С.А. Пшеничнюк, ${ }^{1}$ А.А. Лачинов, ${ }^{1}$ А.Ф. Галиев, ${ }^{1}$ А.Р. Юсупов, ${ }^{2}$ \\ С.Н. Салазкин ${ }^{3}$ \\ ${ }^{1}$ Институт фризики молекул и кристаллов УФИЦ РАН, \\ 450075 Уфра, Россия \\ ${ }^{2}$ Башкирский государственный педагогический университет им. М. Акмуллы, \\ 450008 Уфра, Россия \\ ${ }^{3}$ Институт элементоорганических соединений им. А.Н. Несмеянова РАН, \\ 119991 Москва, Россия \\ e-mail: karamov_danfis@bk.ru
}

Поступило в Редакцию 8 октября 2020 г.

В окончательной редакции 23 ноября 2020 г.

Принято к публикации 25 ноября 2020 г.

\begin{abstract}
Исследовано влияние допирования низкомолекулярным органическим соединением фенолфталеином несопряженного полимера полидифениленфталида. Известно, что фенолфталеин обладает двумя энергетически устойчивыми состояниями - нейтральным и заряженным, возникающими в результате захвата избыточного электрона. Морфологические особенности полимерных пленок контролировались методом атомно-силовой микроскопии. Анализ вольт-амперных характеристик показал, что увеличение концентрации допанта приводит к увеличению проводимости. Установлен нетривиальный факт связи роста проводимости и подвижности носителей заряда с увеличением концентрации допанта. В то же время наличие допанта не приводит к существенному изменению концентрации носителей заряда.
\end{abstract}

Ключевые слова: молекулярное допирование, тонкие полимерные пленки, диэлектрики, полимеры, фенолфталеин.

DOI: $10.21883 / J T F .2021 .05 .50702 .285-20$

\section{Введение}

В электропроводящих полимерах часто уровень проводимости задается введением допанта, его концентрацией [1-7]. В качестве допирующих агентов используются как неорганические соединения, так и органические. В последние годы использование низкомолекулярных органических допантов часто применяется для корректировки (тюнинга) электронных состояний полимерной матрицы, позволяющей повышать эффективность транспорта тех или иных носителей заряда в органических гетероструктурах [1-17]. Это особенно характерно при поиске путей повышения эффективности излучательной рекомбинации экситонов в многослойных электролюминесцентных устройствах, включающих в себя большое количество границ раздела разных материалов $[9,10]$. Как правило, в описанных выше случаях модификации подвергаются органические материалы с делокализованными валентными $\pi$-электронами на основе сопряженных соединений $[1-7,9,10]$. Однако не меньший интерес могут представлять органические соединения с большой шириной запрещенной зоны, к которым относятся несопряженные полимеры $[8,11-18]$. В таких полимерах отсутствует делокализация $\pi$-электронов вдоль полимерной цепи, ограничиваясь пределами мономерного звена. Тем не менее такие органические материалы представляют большой интерес, так как большой энергетический зазор между верхней занятой и нижней вакантной орбиталями позволяет в больших пределах изменять электронные свойства материала. А в случае электролюминесценции, например, обеспечить дефицитный синий источник света $[4,11]$. Известны, например, несопряженные полимеры, тонкие субмикронные пленки которых могут изменять свою проводимость в большом интервале значений $[15,17]$. Не менее интересен выбор органических допантов. Как правило, основной задачей допанта является создание стабильного электронного состояния, приводящего к изменению электронных свойств материала [1]. В то же время не меньший интерес для целей управления процессом генерации и переноса заряда в органической среде могут представлять молекулярные допанты с несколькими энергетически устойчивыми состояниями, переходы между которыми происходят в зависимости от условий взаимодействия с молекулами матрицы $[7,18]$. В частности, известны соединения типа фенолфталеина, которые могут находиться в двух устойчивых состояниях: нейтральном и заряженном, возникающем в результате взаимодействия с избыточным зарядом среды [19].

Целью настоящей работы явилось изучение влияния допирования молекулами фенолфталеина на проводимость субмикронных пленок полидифениленфталида. 


\section{1. Объекты и методы исследования}

В качестве полимерного материала был выбран несопряженный полимер полидифениленфталид (ПДФ), в тонких пленках которого наблюдаются явления зарядовой неустойчивости $[15,20]$, в качестве допирующего соединения - фенолфталеин (ФФ) производства „Alfa Aesar“ (рис. 1, $a, b)$. Выбор ФФ был обусловлен тем, что ранее отмечалось заметное влияние присутствия этого соединения в полимерной матрице на пороговые характеристики электронного переключения тонкопленочного материала. Последнее до сих пор не получило необходимого объяснения. В то же время известно, что при взаимодействии с избыточным электроном структура ФФ может перейти в $\pi$-сопряженное состояние. Предполагалось, что концентрацией избыточных электронов можно будет управлять путем изменения уровня инжекции носителей заряда в полимерную пленку. Тем самым инициировать такой переход внутри полимерной матрицы, влияя на ее проводимость.

Структура образца представляла собой систему металл/полимер/металл (рис. 1,c). Металлические электроды были изготовлены из меди и индия. Медь наносилась методом термодиффузионного напыления в вакууме на поверхность стеклянной пластины. Индиевый электрод был прижимным и формировался путем накатки индиевой фольги на поверхность полимерной пленки.

Пленочные полимерные образцы были изготовлены из 5 wt.\% раствора полимера в циклогексаноне путем его центрифугирования на поверхности медного электрода. После нанесения пленка подвергалась процедуре сушки: на воздухе при комнатной температуре в течение $30 \mathrm{~min}$, затем в течение $40 \mathrm{~min}$ при температуре $150^{\circ} \mathrm{C}$ для удаления остатков растворителя. Фенолфталеин вводился в раствор полимера с расчетом $1,2.5,5,10,15,20$ wt.\% от общей массы сухого вещества.
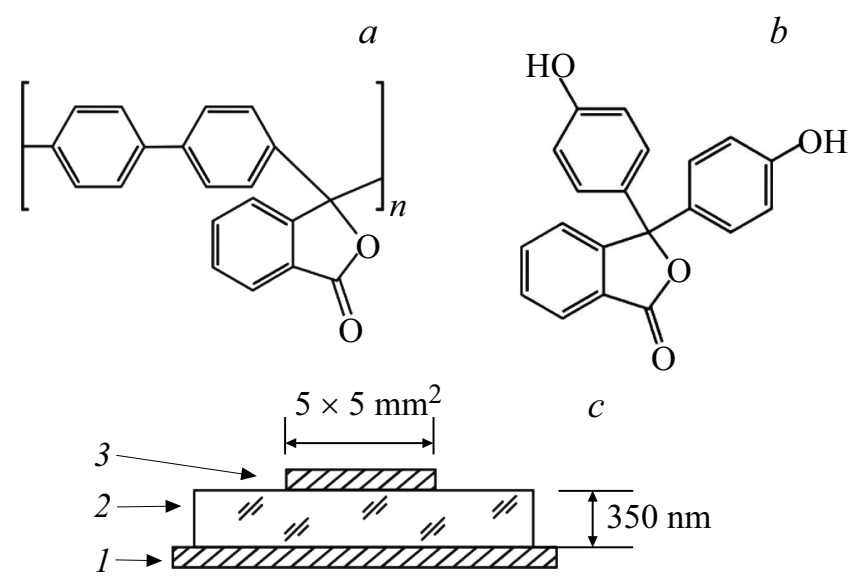

Рис. 1. Структурная формула полидифениленфталида (a) и фенолфталеина $(b)$, схематическое изображение структуры образца $(c): 1$ - металл 1,2 - полимер, 3 - металл 2.
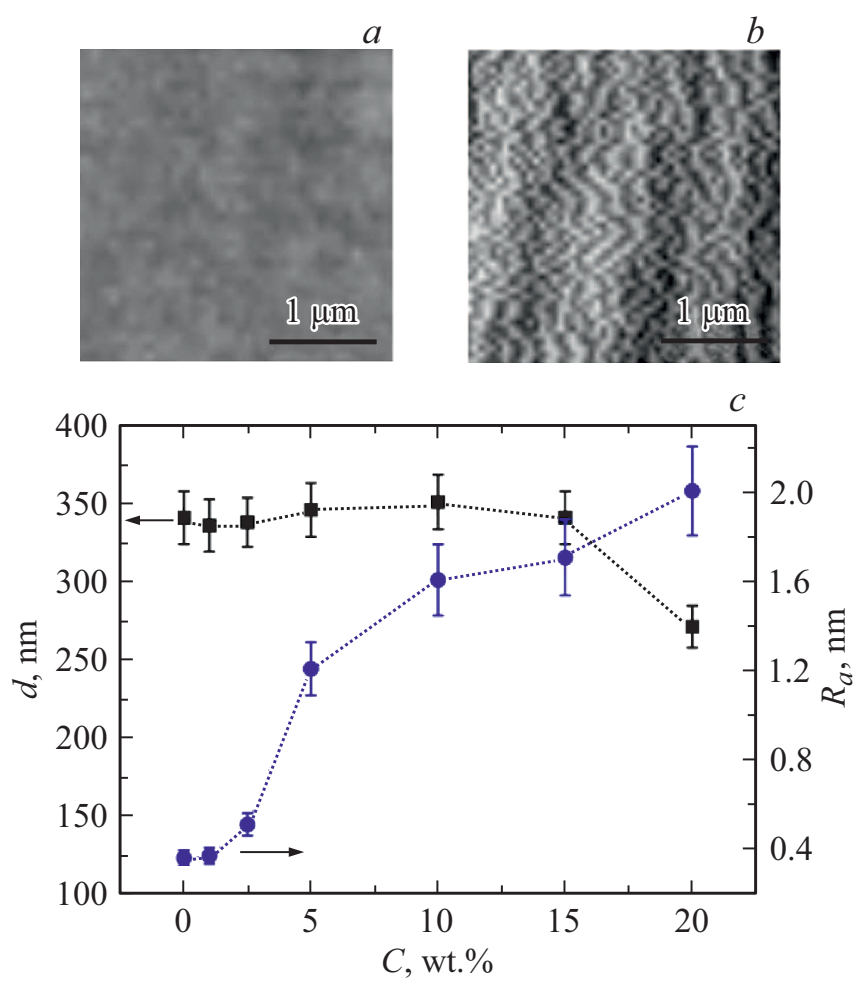

Рис. 2. Результаты анализа изображений поверхности полимерных пленок, полученных методом АСМ. АСМ изображение поверхности полимерной пленки без $Ф \Phi(a)$ и при концентрации ФФ $20 \mathrm{wt} . \%(b)$. Зависимость толщины и среднеарифметической шероховатости тонкой полимерной пленки от весовой концентрации ФФ в полимерной матрице $(c)$.

Исследования вольт-амперных характеристик (BAX) тонких пленок были проведены с помощью источникаизмерителя Keithley 2400 при нормальных условиях. Диапазон использованных напряжений был выбран с учетом инжекционных процессов, происходящих в пленочных образцах и составил 0-2 V. Предварительные измерения показали, что именно в этом интервале напряжений происходит изменение функциональной зависимости тока $(I)$ от приложенного напряжения $(U)$ вида $I \propto k U^{n}$. То есть эта зависимость переходит в сверхлинейный режим при $n>1$, и начинает проявляться инжекционный механизм.

Полученные полимерные пленки были предварительно исследованы методом атомно-силовой микроскопии $(\mathrm{ACM})$. При этом был использован контактно-силовой метод АСМ и подходы представленные ранее в работе [21]. Изучение морфологии пленок показало, что они однородны по толщине, отсутствуют дефекты включения, что указывает на хорошие пленкообразующие свойства растворов полимера и полимера с молекулярным допантом.

Более детальное исследование влияния низкомолекулярного допанта на морфологию тонких пленок было проведено на кремниевых пластинах с характерной локальной шероховатостью поверхности поряд- 
ка $0.1-0.2 \mathrm{~nm}$. На рис. 2 представлены результаты АСМ исследования поверхности полимерной пленки. На рис. 2, $a, b$ представлены АСМ изображения поверхности исходной пленки и допированной при концентрации ФФ 20 wt.\% соответственно. Зависимости толщины и среднеарифметической шероховатости пленок от концентрации допанта показаны на рис. 2,c. Установлено, что толщина полимерной пленки с увеличением концентрации ФФ остается практически неизменной (в рамках погрешности измерения АCM) и лежит в диапазоне 330-350 nm, при этом шероховатость поверхности увеличивается более чем в 5 раз от 0.3 до $2 \mathrm{~nm}$. По-видимому, изменение шероховатости является следствием модификации поверхности полимерной пленки при увеличении концентрации молекул ФФ. Последнее хорошо видно на АСМ изображении, представленном на рис. $2, b$.

Уменьшение толщины пленки при концентрации ФФ на $20 \mathrm{wt} \%$, по-видимому, является следствием уменьшения вязкости исходного раствора ПДФ+ФФ из-за увеличения концентрации низкомолекулярной компоненты.

\section{2. Полученные результаты и их обсуждение}

Типичные BAX экспериментальных структур представлены на рис. 3. Анализ результатов измерений показал, что BAX имеют нелинейный вид для всех рассмотренных концентраций фенолфталеина. Наибольшее значение проводимости пленок наблюдается при содержании примеси $20 \mathrm{wt} . \%$, наименьшее - для чистого ПДФ.

На всех ВАХ можно выделить омический участок $I \propto U^{n}(n=1)$ при малых напряжениях, и сверхлинейный участок $I \propto U^{n}(n>1)$. Такое поведение $\mathrm{BAX}$ свойственно для не допированных тонких пленок ПДФ

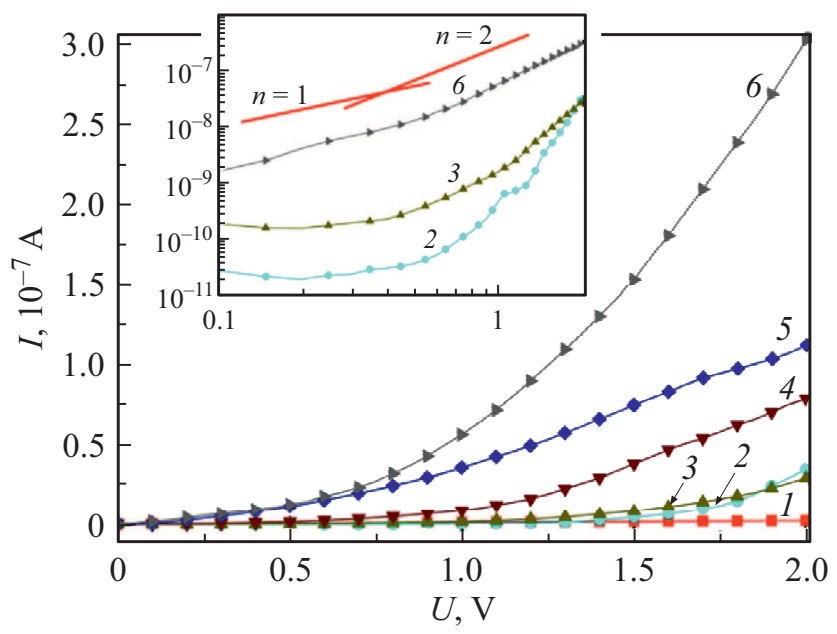

Рис. 3. ВАХ тонких пленок ПДФ с различным содержание фенолфталеина $(1-0,2-1,3-2.5,4-5,5-10$, $6-20$ wt.\%). На вставке ВАХ в логарифмических координатаx.



Рис. 4. Зависимость подвижности и концентрации носителей зарядов от содержания примесных молекул.

и хорошо согласуется с инжекционной моделью [22-24]. Согласно теории токов, ограниченных объемным зарядом [24], смена наклона ВАХ происходит, когда концентрация инжектированных носителей заряда начинает превышать концентрацию собственных. По положению данной точки на ВАХ можно провести оценку равновесной концентрации собственных основных носителей заряда, а также значения их подвижности. Равновесная концентрация находилась из условия равенства значений тока для линейного и квадратичного участков зависимости тока от напряжения в точке перегиба:

$$
\begin{aligned}
& j_{1}=\frac{e n_{0} \mu U_{n}}{L}, \\
& j_{2}=\frac{\varepsilon \varepsilon_{0} \mu U_{n}^{2}}{L^{3}},
\end{aligned}
$$

где $j$ - плотность тока, $L-$ расстояние между электродами, $U_{n}$ - напряжение, соответствующее точке перехода, $n_{0}$ - равновесная концентрация носителей заряда, $\mu$ - максимальная подвижность носителей заряда, $e$ - элементарный электрический заряд. Отсюда, приравняв (1) и (2), получаем выражение для концентрации:

$$
n_{0}=\frac{\varepsilon \varepsilon_{0} U_{n}}{e L^{2}}
$$

Подвижность носителей рассчитывалась по следующей формуле:

$$
\mu=\frac{j L^{3}}{\varepsilon \varepsilon_{0} U_{n}^{2}} .
$$

Необходимо отметить, что оценка $\mu$ по формуле (4) дает в данном случае минимальное значение подвижности инжектированных носителей. На рис. 4 представлены зависимости равновесной подвижности и концентрации носителей зарядов от содержания примесных молекул, полученные из анализа ВАХ в рамках инжекционной модели. Из построенных зависимостей видно, что изменение проводимости с увеличением процентного содержания молекул ФФ в объеме пленки 
полидифениленфталида обусловлено ростом подвижности носителей заряда. Оценка равновесной концентрации носителей заряда показала, что в рассматриваемом температурном диапазоне концентрация практически не изменялась (рис. 4).

Для анализа влияния изменения параметров контакта на границе In/полимер на транспорт носителей заряда была проведена оценка высоты потенциального барьера для электронов в зависимости от концентрации допанта. Ранее в работах [25-27] было показано, что преобладающим механизмом переноса заряда в структуре металл-ПДФ-металл при комнатных температурах и аналогичных полях является термоэлектронная эмиссия Шоттки. В этом случае плотность тока термоэлектронной эмиссии с учетом понижения барьера за счет приложенного внешнего поля задается уравнением (5):

$$
j=A^{* *} T^{2} \exp \left(-\frac{e \varphi_{B 0}}{k T}\right) \exp \left(-\frac{e(\Delta \varphi+V)}{k T}\right),
$$

где $j-$ плотность тока, $\varphi_{B 0}-$ асимптотическое значение высоты потенциального барьера при нулевом поле, $A^{* *}$ - эффективная постоянная Ричардсона, $\Delta \varphi-$ понижение барьера за счет эффекта Шоттки, $V$ приложенное напряжение.

Учитывая, что в настоящей работе основная задача оценка относительного изменения высоты потенциального барьера на границе металл/полимер в зависимости от концентрации допанта, то допустимо применение метода полного тока для определения высоты барьера, согласно выражению [27]:

$$
\varphi_{B}=\frac{k T}{e} \ln \left(\frac{S A^{* *} T^{2}}{I_{s}}\right),
$$

где $T$ - температура, $k$ - постоянная Больцмана, $e-$ заряд электрона, $S$ - площадь контакта, $A^{* *}-$ постоянная Ричардсона, $I_{S}$ - ток насыщения. Ток насыщения находится из пересечения линейной аппроксимации ВАХ в полулогарифмических координатах $(\ln (I)-U)$ с осью $U=0$.

Рассчитанная высота потенциального барьера контакта индий/полимер (ПДФ) (рис. 5) завышена по сравнению со значением $\varphi_{B} \approx 0.39 \mathrm{eV}$, полученным в работе [25]. Однако относительное изменение высоты барьера в зависимости от концентрации допанта не более $5 \%$ и в рамках погрешности применяемой модели практически не меняется.

Теоретическая интерпретация транспорта носителей заряда молекулярно допированых полимера базируется на аналитических моделях Гауссова беспорядка [28-31]. В частности, модель переноса заряда в слабо и сильно допированных органических полупроводниках [30,31], основанная на кулоновском взаимодействии носителей заряда с ионизированными примесями, довольно точно описывает транспорт носителей заряда в допированных Р3НТ. Однако выбор модели в нашем случае не однозначен. Тем не менее ключевым параметром,

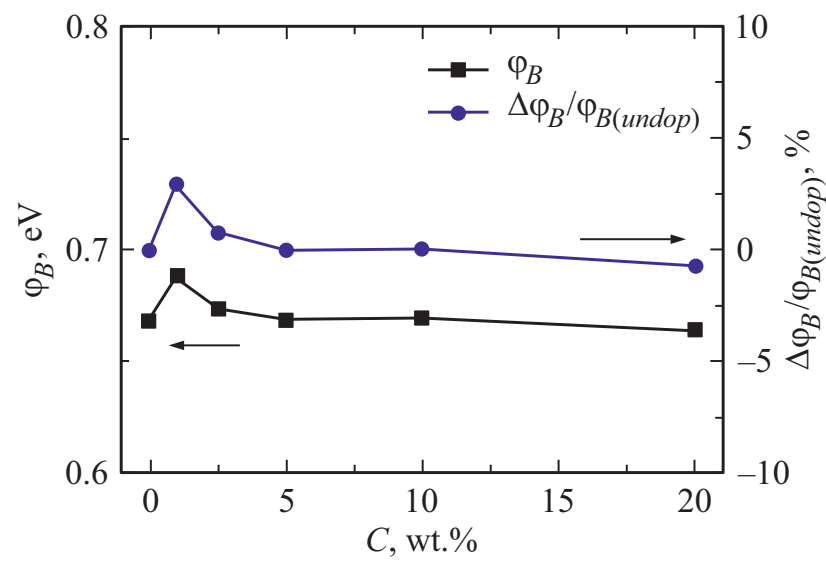

Рис. 5. Высота потенциального барьера на контакте металл/полимер без учета эффекта Шоттки и относительное изменение потенциального барьера $\Delta \varphi_{B} / \varphi_{B}$ (undop) в зависимости от концентрации допанта $\left(\varphi_{B}\right.$ (undop) - высота потенциального барьера при нулевой концентрации допанта).

определяющим этот перенос, является смещение уровня энергии между НОМО „хозяина“-полимерной матрицы и LUMO „гостя“"-допанта [1-7,30,31].

Влияние материала гостя на подвижность и проводимость материала хозяина систематически изменяется в зависимости от энергии LUMO гостей относительно НОМО хозяина. Для гостей с энергией LUMO в пределах $\pm 0.5 \mathrm{eV}$ от энергии НОМО доминирующим процессом, регулирующим транспорт, является конкуренция между образованием глубокого хвоста в DOS и заполнением электронных состояний [2]. В других случаях во взаимодействии с хозяином доминируют любые полярные боковые группы „гостя“ $[2,29]$ и изменения в морфологии „хозяина“. Для относительно аморфных материалов хозяев последнее взаимодействие может привести к подавлению глубоких ловушек, вызывая неожиданное увеличение подвижности на 1-2 порядка.

\section{Заключение}

Допирование ПДФ фенолфталеином влияет на электрическую проводимость тонких пленок, которая увеличивается с ростом концентрации ФФ в объеме полимера. При этом наличие ФФ не влияет на концентрацию собственных носителей заряда и высоту потенциального барьера на контакте металл/полимер. Последнее, повидимому, обусловлено близким электронным строением мономерного звена ПДФ и молекулы ФФ, при котором энергии нижних вакантных и верхних занятых орбиталей практически совпадают. Увеличение проводимости обусловлено существенным ростом подвижности носителей заряда, что может свидетельствовать о формировании дополнительных центров переноса заряда. Малое напряжение перехода от линейного к сверхлинейному участку BAX, связанное с достижением инжектированных зарядов концентрации собственных носителей, 
косвенно свидетельствует о близком к уровню Ферми энергии этих центров переноса. Полученные результаты свидетельствуют о целесообразности применения фенолфталеина в качестве бистабильного молекулярного допанта для изменения проводимости тонких пленок несопряженного полимера ПДФ.

\section{Финансирование}

Работа выполнена при поддержке гранта РНФ № 1913-00021.

\section{Конфликт интересов}

Авторы заявляют, что у них нет конфликта интересов.

\section{Список литературы}

[1] P. Kar. Doping in conjugated polymers (John Wiley \& Sons, 2013)

[2] G. Zuo, Z. Li, O. Andersson, H. Abdalla, E. Wang, M. Kemerink. J. Phys. Chem. C, 121 (14), 7767 (2017). DOI: $10.1021 /$ acs.jpcc.7b01758

[3] B. Lussem, C.M. Keum, D. Kasemann, B. Naab, Z. Bao, K. Leo. Chem. Rev., 116 (22), 13714 (2016). DOI: 10.1021/acs.chemrev.6b00329

[4] K. Walzer, B. Maennig, M. Pfeiffer, K. Leo. Chem. Rev., 107 (4), 1233 (2007). DOI: 10.1021/cr050156n

[5] Y. Xu, H. Sun, A. Liu, H.H. Zhu, W. Li, Y.F. Lin, Y.Y. Noh. Adv. Mater., 30 (46), 1801830 (2018). DOI: $10.1002 /$ adma. 201801830

[6] I. Salzmann, G. Heimel, M. Oehzelt, S. Winkler, N. Koch. Acc. Chem. Res., 49 (3), 370 (2016). DOI: $10.1021 /$ acs.accounts. 5 b00438

[7] I.E. Jacobs, A.J. Moulé. Adv. Mater., 29 (42), 1703063 (2017). DOI: 10.1002/adma.201703063

[8] T. Schneider, F. Limberg, K. Yao, A. Armin, N. Jürgensen, J. Czolk, H. Krüger. J. Mater. Chem. C, 5 (3), 770 (2017). DOI: $10.1039 / \mathrm{C} 6 \mathrm{TC} 02346 \mathrm{~K}$

[9] H. Yan, Y. Tang, X. Sui, Y. Liu, B. Gao, X. Liu, F.Sh. Liu, J. Hou, W. Ma. ACS Energy Lett., 4 (6), 1356 (2019). DOI: $10.1021 /$ acsenergylett.9b00843

[10] D. Di, L. Yang, J.M. Richter, L. Meraldi, R.M. Altamimi, A.Y. Alyamani, D. Credgington, K.P. Musselman, J.L. MacManus-Driscoll, R.H. Friend. Adv. Mater., 29 (13), 1605987 (2017). DOI: 10.1002/adma.201605987

[11] M.Y. Wong. J. Electr. Mater., 46 (11), 6246 (2017). DOI: $10.1007 / \mathrm{s} 11664-017-5702-7$

[12] L. Zeng, T.Y.H. Lee, P.B. Merkel, S.H. Chen. J. Mater. Chem., 19 (46), 8772 (2009). DOI: 10.1039/B909787B

[13] J. Van Cleave, S. Jaju, M. Thakur. J. Macrom. Sci. A, 54 (8), 543 (2017). DOI: 10.1080/10601325.2017.1320778

[14] M. Woodhouse, C.L. Perkins, M.T. Rawls, R.A. Cormier, Z. Liang, A.M. Nardes. J. Phys. Chem. C, 114 (14), 6784 (2010). DOI: $10.1021 /$ jp910738a

[15] А.Н. Лачинов, Н.В. Воробьева. УФН, 176 (12), 1249 (2006). DOI: 10.3367/UFNr.0176.200612a.1249

[A.N. Lachinov, N.V. Vorob'eva. Phys. Usp., 49, 1223 (2006). DOI: 10.1070/PU2006v049n12ABEH006176]
[16] U. Ali, K.J.B.A. Karim, N.A. Buang. Pol. Rev., 55 (4), 678 (2015). DOI: 10.1080/15583724.2015.1031377

[17] N.M. Shishlov, S.I. Maslennikov, S.S. Akhmetzyanov, V.N. Khrustaleva, N.G. Gileva, A.A. Yakovleva. Doklady Phys. Chem., 394, 27 (2004). DOI: 10.1023/B:DOPC.0000014762.68209.e8

[18] J. Kai, M.C. Felinto, L.A. Nunes, O.L. Malta, H.F. Brito. J. Mater. Chem., 21, 3796 (2011). DOI: $10.1039 / \mathrm{C} 0 \mathrm{JM} 03474 \mathrm{~F}$

[19] N.L. Asfandiarov, A. Modelli, S.A. Pshenichnyuk, R.G. Rakhmeev, M.M. Tayupov, E.E. Tseplin, S.N. Tseplina.J. Chem. Phys., 151, 134302 (2019). DOI: $134302.10 .1063 / 1.5119777$

[20] С.Н. Салазкин, В.В. Шапошникова, Л.Н. Мачуленко, Н.Г. Гилева, В.А. Крайкин, А.Н. Лачинов. ВМС. Серия А, 50 (3), 399 (2008). [S.N. Salazkin, V.V. Shaposhnikova, L.N. Machulenko, N.G. Gileva, V.A. Kraikin, A.N. Lachinov. Pol. Sci. A, 50, 243 (2008). DOI: $10.1134 / \mathrm{S} 0965545 \mathrm{X} 08030024]$

[21] Д.Д. Карамов, В.М. Корнилов, А.Н. Лачинов, В.А. Крайкин, И.А. Ионова. ЖТФ, 86 (7), 124 (2016). [D.D. Karamov, V.M. Kornilov, A.N. Lachinov, V.A. Kraikin, I.A. Ionova. Tech.Phys., 61, 1085 (2016). DOI: $10.1134 / 2$ FS106378421607015X]

[22] А.А. Бунаков, А.Н. Лачинов, Р.Б. Салихов. ЖТФ, 73 (5), 104 (2003). [A.A. Bunakov, A.N. Lachinov, R.B. Salikhov. Tech. Phys., 48, 626 (2003). DOI: 10.1134/1.1576480]

[23] А.Р. Тамеев, А.Н. Лачинов, Р.Б. Салихов, А.А. Бунаков, A.B. Ванников. ЖФХ, 79 (12), 2266 (2005). [A.R. Tameev, A.V. Vannikov, A.N. Lachinov, R.B. Salikhov, A.A. Bunakov. Russ. J. Phys. Chem. A, 79 (12), 2025 (2005) DOI:10.1134/S106378341101032X]

[24] М. Ламперт, П. Марк. Инжекиионные токи в твердых mелах (Мир, М., 1973)

[25] И.Р. Набиуллин, А.Н. Лачинов, А.Ф. Пономарев. ФТТ, 54 (2), 230 (2012) [I.R. Nabiullin, A.N. Lachinov, A.F. Ponomarev. Phys. Solid State. 54, 243 (2012). DOI: $10.1134 / \mathrm{S} 1063783412020199]$

[26] А.Р. Юсупов, Р.Г. Рахмеев, А.Н. Лачинов, Л.Р. Калимуллина, А.С. Накаряков, А.А. Бунаков. ФТТ, 55 (7), 1392 (2013) [A.R. Yusupov, L.R. Kalimullina, A.S. Nakaryakov, A.A. Bunakov, R.G. Rakhmeev, A.N. Lachinov. Phys. Solid State, 55 (7), 1494 (2013). DOI: $10.1134 / \mathrm{S} 1063783413070342]$

[27] И.Р. Набиуллин, Р.М. Гадиев, А.Н. Лачинов. ФТТ, 61 (6), 1184 (2019). DOI: 10.21883/JTF.2021.05.50702.285-20 [I.R. Nabiullin, R.M. Gadiev, A.N. Lachinov. Phys. Solid State, 61 (6), 1122 (2019). DOI: 10.1134/S1063783419060155]

[28] А.П. Тютнев, А.В. Никеров, Д.Д. Смирнов, С.Р. Тумковский. ВMC. Серия А, 58 (2), 199 (2016). DOI: 10.7868/S230811201602019X [A.P. Tyutnev, A.V. Nikerov, D.D. Smirnov, S.R. Tumkovskii. Pol. Sci. A, 58, 276 (2016). DOI: $10.1134 / \mathrm{S} 0965545 \mathrm{X} 1602019 \mathrm{X}]$

[29] R.H. Young, J.J. Fitzgerald. J. Chem. Phys., 102 (5), 2209 (1995). DOI: $10.1063 / 1.468742$

[30] G. Zuo, H. Abdalla, M. Kemerink. Phys. Rev. B, 93 (23), 235203 (2016). DOI: 10.1103/PhysRevB.93.235203

[31] V.I. Arkhipov, E.V. Emelianova, P. Heremans, H. Bässler. Phys. Rev. B, 72 (23), 235202 (2005). DOI: $10.1103 /$ PhysRevB.72.235202 